\title{
Induction of oestrus in the camel (Camelus dromedarius) during seasonal anoestrus
}

\author{
E. Elias, E. Bedrak* and D. Cohen \\ Isan Center for Comparative Medicine, Blaustein Institute for Desert Research and \\ *Department of Biology, Ben-Gurion University of the Negev, Beer-Sheva 84105, Israel
}

\begin{abstract}
Summary. Injection of 7000 i.u. PMSG induced oestrus in 7 camels during the last part of seasonal anoestrus. Mature follicles developed and a $\mathrm{CL}$ was formed after fertile mating. However, pregnancy was not maintained by Day 60 in the 3 females detected as pregnant by rectal palpation and increased progesterone concentrations at Day 50 . A single male camel mated with 4 of the females 2-16 days after the PMSG injection, and 2 or 3 matings occurred. The failure of pregnancy after induction of oestrus and mating during seasonal anoestrus was probably due to inadequate luteal function.
\end{abstract}

\section{Introduction}

The one-humped camel (Camelus dromedarius) is a seasonal breeder with a relatively short breeding period, when increased ovarian activity is exhibited (Shalash, 1965, 1980; Nawito, Shalash, Hoppe \& Rakha, 1967; Novoa, 1970). In Israel, the normal breeding season occurs from December to early April. Female camels come into heat during this period and exhibit mainly follicular activity; there is no cyclic luteal phase (Nawito et al., 1967; Musa \& Abusineina, 1978b; Shalash, 1980; Elias, Bedrak \& Yagil, 1984a). The follicular wave covers the period of time between the acceptance of the male by the female, with the associated changes in the ovaries, and her reacceptance of the male, indicating the start of a new wave (Nawito et al., 1967; Shalash, 1980). Nawito et al. (1967) divided the follicular wave into the (a) mature follicular stage; (b) atretic follicular stage; (c) non follicular stage; and (d) growing follicular stage. Ovulation in the camel does not occur spontaneously, as in the cow, ewe or goat, and the copulatory stimulus for its induction is indispensable (Nawito et al., 1967; Novoa, 1970; Shalash, 1980; Elias et al., 1984a).

Studies of the reproductive endocrine cycle of the male camel in Israel (Bodenheimer, 1954; Yagil \& Etzion, 1980; Bedrak, Rosenstrauch, Kafka \& Friedländer, 1983) have shown that the male has pronounced sexual activity from December to March or April, as indicated by hormonal and behavioural changes. In the non-breeding season there is reduced testicular activity (Sharma, 1981 ; Bedrak et al., 1983; Friedländer, Rosenstrauch \& Bedrak, 1984) associated with decreased serum testosterone concentrations (Yagil \& Etzion, 1980; Bedrak et al., 1983). It is generally accepted that the male camel has a period of sexual activity which corresponds to the oestrous period of females (Volcani, 1954; Charnot, 1964; Abdel-Raouf, Fateh El-Bab \& Owaida, 1975; Yagil \& Etzion, 1980).

The objectives of the present study were to: (1) investigate whether oestrus can be induced in the camel during seasonal anoestrus; (2) measure the blood concentrations of oestradiol and progesterone after treatment with PMSG during seasonal anoestrus in mated and unmated camels; and (3) attempt to alter the hormonal profile so as to produce successful pregnancy. Extension of the breeding season of camels is of great economic importance because camels could become a major source of animal protein in drought-stricken areas. 


\section{Materials and Methods}

Animals. Sexually mature female camels $(\mathrm{N}=7)$ were used: 2 camels serving as controls were not allowed to mate but the remaining 5 animals were allowed to mate (experimental group). A single adult male was used for breeding throughout the experiment. This male was housed next to the experimental females before and during the experiment.

Physical examination. The 5 experimental camels were examined by rectal palpation before the start of the experiment, on the day of mating, and 10 and 50 days after the last mating. The 2 control females were also examined by rectal palpation before the start of the experiment and 10 days after a single PMSG injection. The objectives of rectal palpation were to determine the presence or absence of mature follicles, and a corpus luteum (CL) and to diagnose pregnancy (possible at 50 days after the last mating according to Musa \& Abusineina, 1978a). When mating was not followed by conception (sterile mating, when the $\mathrm{CL}$ is generally not developed and blood progesterone concentration is $<1 \mathrm{mg} / \mathrm{ml}$ : Elias et al., 1984a), rectal palpation was not performed 10 days after mating, except for Camel 6 (Text-fig. 1), in which oestrus recurred 7 days after the first mating. Oestrus was identified by the acceptance of the male for mating (Nawito et al., 1967) and the presence of mature follicles, as detected by rectal palpation (Elias et al., 1984b). Libido was checked daily $(08: 00$ and $18: 00 \mathrm{~h})$ before and after induction of oestrus by exposing all the females to the male for $30 \mathrm{~min}$. Although all the females were exposed to the male, only the 5 experimental camels were allowed to mate. This procedure was employed from Day 2 to Day 20 after the injection of PMSG. Immediately after mating, a sample of semen was collected from the vagina (cotton swabs) and examined by routine procedures for motility and abnormality of spermatozoa.

Induction of oestrus and collection of blood samples. All 7 female camels were treated with a single intramuscular injection of PMSG (7000 i.u. Vetserigon, product of Israel Agriculture) on 11 October $1982(09: 00 \mathrm{~h})$. Blood samples were taken from the females 5 days before PMSG injection and every day between $08: 30$ and $9: 30 \mathrm{~h}$ up to 20 days after injection, and every 5 days during the period 20-30 days after the last mating. In the period 30-60 days after the last mating, females were bled every 10 days (between $08: 30$ and $09: 30 \mathrm{~h}$ ) on the days specified (Text-fig. 2). Blood samples were also taken from the male at various periods throughout the experiment, i.e. 5 days before the injection of PMSG into the females, and $10 \mathrm{~min}$ before and $30 \mathrm{~min}$ after mating. The procedures for blood sampling and handling of serum were as previously described (Elias et al., 1984a).

Hormone measurements. The concentrations of progesterone and testosterone in the serum were determined by radioimmunoassay as described in detail previously (Bedrak, Chap \& Fried, 1979; Elias et al., 1984a). In brief, if the sensitivity of the method is defined as the least amount of unlabelled steroid which significantly displaces the labelled steroid from the antibody-labelled steroid complex, then $12.5 \mathrm{pg}$ was significantly different from the zero point at an antiserum dilution $1: 10000$ (for progesterone) or $1: 16000$ (for testosterone). Thus, the routine working range covered by the standard curve was 12.5 to $800 \mathrm{pg}$. The values for the coefficient of variation in the intra-assay and interassay measurements carried out with each method were, respectively, less than $11 \%$ and $17 \%$ for progesterone, $4.2 \%$ and $9.3 \%$ for testosterone. The concentration of oestradiol- $17 \beta$ in the serum was determined by RIA (kit purchased from Iso-Pac Limited, Jerusalem, Israel). The minimum sensitivity, intra-assay and interassay coefficients of variation were $12.5 \mathrm{pg} / \mathrm{ml}, 6 \%$ and $20 \%$, respectively.

\section{Results}

Induction of oestrus after PMSG injection

The appearance of oestrus after PMSG injection varied from 2 to 16 days (Text-fig. 1). The duration of oestrus was 2-3 days, and the interval between two consecutive periods of oestrus was 


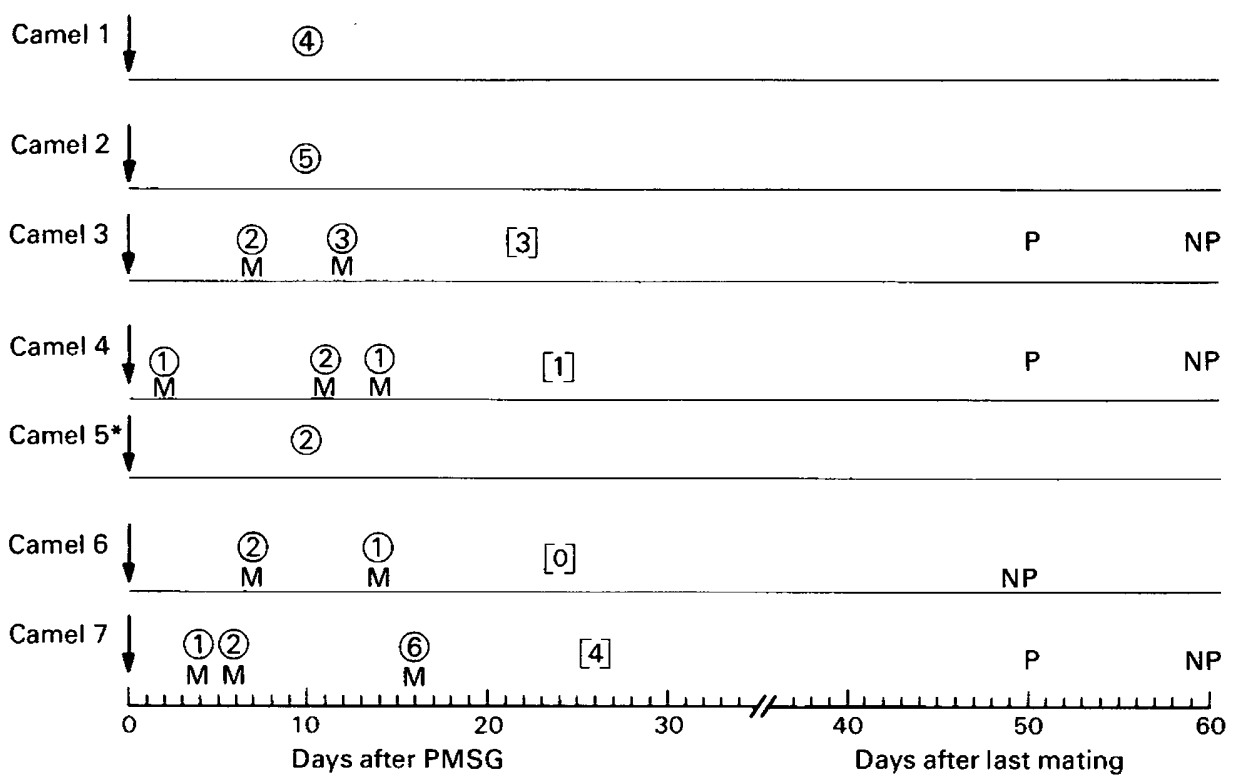

Text-fig. 1. Induction of oestrus in camels during seasonal anoestrus by a single PMSG injection (7000 i.u./animal). Camels 1 and 2 were not allowed to mate; Camels 3-7 were allowed to mate. $\downarrow$, Day of PMSG injections; M, mating; encircled figures represent number of mature follicles present on day of mating, bracketted numbers represent number of corpora lutea detected by rectal palpation after last mating or 10 days after PMSG injection; $P$, pregnancy confirmed by rectal palpation; NP, no pregnancy. ${ }^{*}$ Male showed no interest in this camel despite the fact that she was in oestrus.

5-10 days. In the 2 controls, oestrus began 5 days after injection and lasted 14-17 days, as it did in the camel from the experimental group that did not mate. Oestrus recurred several times in all the camels, including those that conceived (Text-fig. 1).

\section{Physical changes revealed by rectal palpation}

Rectal palpation revealed quiescent ovaries (absence of follicles and corpora lutea) in all camels before the start of the experiment. In all 7 camels rectal palpation after the PMSG injection revealed variable numbers of mature follicles, mainly in the left ovary (Text-fig. 1). In 3 out of the 4 camels that mated, conception took place (fertile mated camels), as determined by rectal palpation on Day 50 after the last mating (Text-fig. 1), and on Day 10 after mating, CL were palpated on the left ovary (Text-fig. 1). In these 3 females, the pregnant left uterine horn was larger and softer than the non-pregnant one on Day 50 after the last mating. The increase in size was uniform throughout its length. These findings, the presence of a CL and a higher serum progesterone concentration (Text-fig. 2b) confirmed pregnancy in these camels. The physical examination on Day 60 revealed that the $\mathrm{CL}$ of pregnancy had undergone partial regression (as compared with that determined previously by rectal palpation), and both uterine horns contracted upon touch with a slow increase in the tone of the uterus. The level of progesterone dropped markedly (Text-fig. 2b). These findings suggested that pregnancy was interrupted between Days 50 and 60 after the last mating. No CL were found in the unmated camels on Day 10 after PMSG injection (Camels 1, 2 and 5) or in Camel 6 which mated but did not conceive 10 days after the last mating. 
The sexual behaviour of the male

The male showed an increased libido which paralleled the time when females became oestrous. The black, odoriferous, sticky, viscous secretion from the neck glands of the male was present 3 days after PMSG injection into the females. The largest quantity of this secretion appeared on Days 6-11 after the PMSG injection. At the first mating, $60 \%$ of spermatozoa were motile. The motility increased to $80 \%$ in the next mating ( 4 days after injection), and this level was maintained for about 2 weeks. The frequency of abnormal spermatozoa was less than $4 \%$. The duration of mating $(n=$ 10, Text-fig. 1) was $5 \cdot 21 \pm 1.2 \mathrm{~min}$.

\section{Serum concentrations of oestradiol}

Concentrations rose irregularly 2 days after injection (Text-fig. 2a). Two peaks were noted in Camels 3, 4 and 7 (fertile) on Days 11 and 16 after injection; 2 peaks were also observed in Camels 1 and 2 (controls) on Days 9 and 15. However, by 16 days after the PMSG injection (early pregnancy)
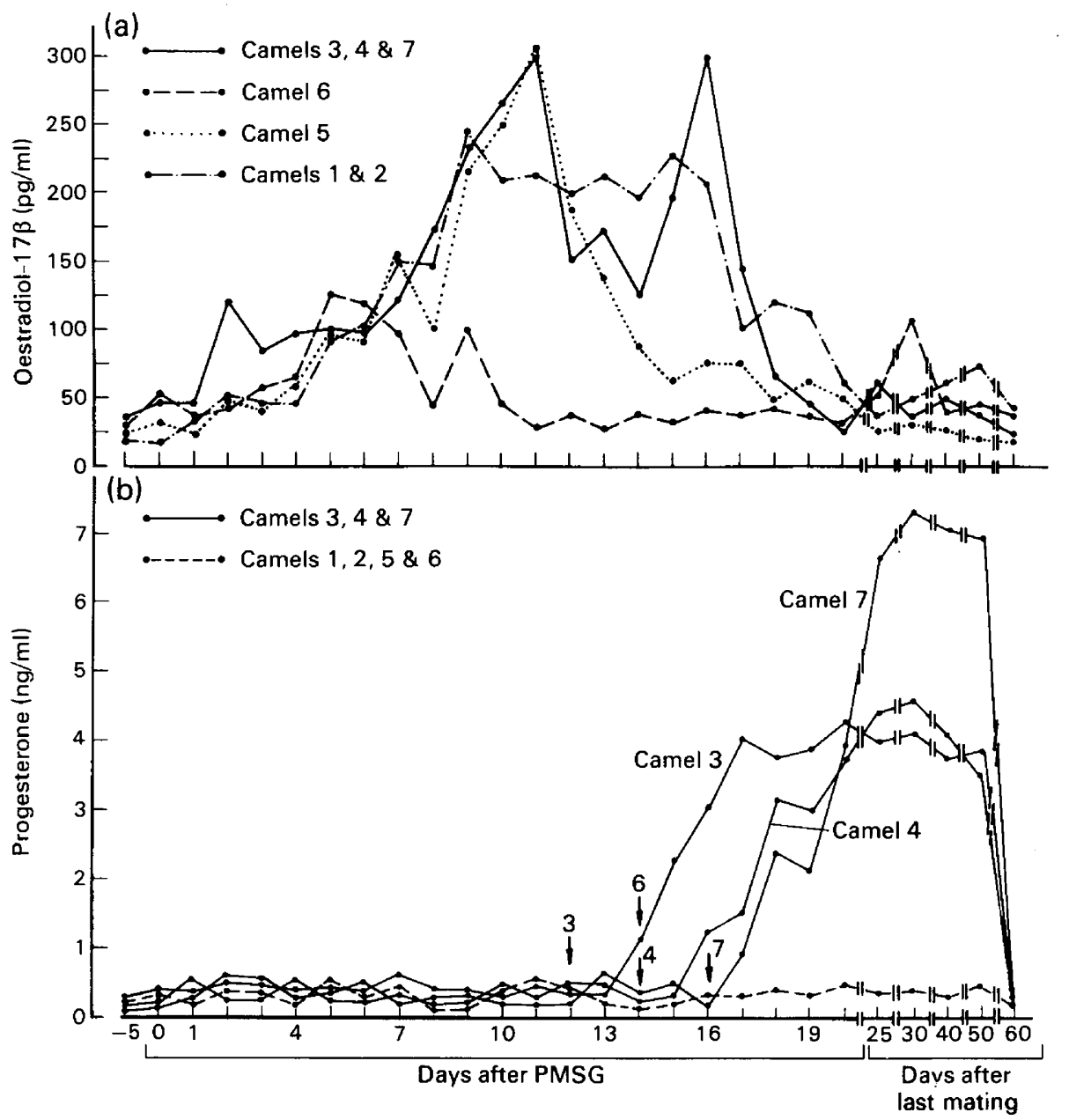

Text-fig. 2. Serum concentrations of (a) oestradiol-17 $\beta$ and (b) progesterone in camels. Induction of oestrus was achieved by a single PMSG injection (7000 i.u./animal) on Day 0 (all females) which was followed by mating (Camels 3, 4, 6 \& 7) and early pregnancy (Camels 3,4 \& 7). In (b) arrows indicate day of mating for Camels 3, 4, 6 and 7. 
oestradiol values gradually decreased (Text-fig. 2a), concomitant with the rise in progesterone concentration (Text-fig. 2b). The unmated females (Nos 1, 2 and 5) showed a single peak in serum oestradiol (Text-fig. 2a), which was almost identical with the first peak detected for the fertile camels.

\section{Serum concentrations of progesterone}

In all camels progesterone concentrations were $<0.6 \mathrm{ng} / \mathrm{ml}$ before the start of the experiment. In Camels 3, 4 and 7 the progesterone values increased to $>1 \mathrm{ng} / \mathrm{ml}$ within $2-3$ days after mating (Text-fig. 2b).

\section{Serum concentrations of testosterone}

Testosterone value in the male was $1.6 \mathrm{ng} / \mathrm{ml} 5$ days before the injection of PMSG into the female camels. However, the value was $28 \cdot 6 \pm 2 \cdot 1 \mathrm{ng} / \mathrm{ml} 10 \mathrm{~min}$ before mating and dropped to $18 \cdot 3$ $\pm 3.8 \mathrm{ng} / \mathrm{ml}$ at $30 \mathrm{~min}$ after mating. The testosterone concentration in the neck gland secretion collected on the day of mating $(n=6)$ was $24 \cdot 6 \pm 4 \cdot 3 \mathrm{ng} / \mathrm{ml}$.

\section{Discussion}

The results obtained in this study indicate that oestrus can be induced in camels with PMSG during seasonal anoestrus. Variability in serum oestradiol concentrations amongst the animals treated with PMSG probably reflected variability in the ovarian response. The action of PMSG has been well studied in different species including the ewe (Dott, Hay, Cran \& Moor, 1979), rat (de Reviers \& Mauleon, 1973), and heifer (Moniaux, Chupin \& Saumande, 1983; Monniaux, Mariana \& Gibson, 1984), but no data are available for the camel, except for the observations by Yuzlikaev \& Akhmediev (1965) who reported that injection with PMSG during the breeding season induced oestrus and resulted in a $100 \%$ calving rate.

Oestradiol levels reported here for the control and fertile mated camels were higher than those observed in heifers injected with PMSG (Monniaux et al., 1983). As in cattle (Staigmiller, 1982), no correlation was noted between the numbers of mature follicles and the serum oestradiol concentration. The variability in the number of mature follicles observed (Text-fig. 1) is probably due to individual characteristics of the animals. There is more than one mature follicle in $18 \%$ of camels (Nawito et al., 1967). This suggests that regulation of follicular growth differs between camels, as reported for heifers (Monniaux et al., 1983). It was possible to palpate mature follicles 10 days after PMSG injection (Text-fig. 1), because the follicles in unmated camels remained unchanged for 10-13 days after reaching maturity (Musa \& Abusineina, 1978b; Elias et al., 1984b). Recurrence of the signs of oestrus (1-3 times) between 2 and 16 days after injection suggests that follicular activity is continuous, similar to the "follicular wave" described in the breeding season (Shalash, 1965, 1980; Nawito et al., 1967).

The interruption of pregnancy at 50-60 days after mating was probably provoked by the drop in the level of progesterone (Text-fig. 2b) from the short-lived $\mathrm{CL}$ that formed after injection with PMSG in seasonal anoestrus. The same phenomena occurred after injection of hCG during the breeding season, with subsequent disappearance of the CL at Day 32 post coitum (Nawito et al., 1967). This weak functioning and the short duration of progesterone synthesis during seasonal anoestrus adversely affects the implantation of the embryo, causing degeneration 50-60 days after fertile mating. If we consider the correlation between the length of pregnancy in the dromedary camel ( $399 \pm 2 \cdot 1$ days: Mehta, Prakash $\&$ Singh, 1962) and embryo size, the embryo size at Day 50 should be $8-10 \mathrm{~cm}$. This is similar to the size of the horse embryo at 30-50 days (gestation period 340 days) (Arthur, 1975). Embryonic mortality appears to be a major cause of low fertility in the camel (Nawito et al., 1967; Shalash, 1980) but little is known about this problem (Novoa, 1970). 
Shalash (1965) showed that the CL in the camel is formed only during pregnancy and found a few animals in which the cervix was patent. Novoa (1970) suggested that cervical patency occurred in pseudopregnant animals, but pseudopregnancy in the camel has not been described in the literature.

The increase in serum testosterone concentrations in the male coincided with the time of oestrus of the females after PMSG injection. The occurrence of spermatogenesis (Friedlander et al., 1984) and steroidogenesis (Bedrak et al., 1983) in the testes of the camel during the non-breeding season suggests that, if given the proper stimulus (such as that provoked by the female camels injected with PMSG in the present study), the male should be able to breed. Indeed the high levels of testosterone in the serum and in the secretion of the neck-glands confirm that the male camel used in this study was sexually active. Also, the motility of spermatozoa increased with consecutive matings. The male camel's response to females in oestrus is more rapid than that of other seasonally breeding species. Moreover, in the non-mating season the male camel reduced spermatogenesis, but never complete aspermatogenesis (Bodenheimer, 1954; Volcani, 1954; Charnot, 1964; Nawito et al., 1967; Friedlander et al., 1984) in contrast with some other non-domesticated ungulates, in which complete aspermatogenesis exists (Abdel-Raouf et al., 1975). The presence of female camels in heat, probably accelerated by olfactory stimulation (via pheromones), leads to an increase in sexual activity in the male at the end of the non-mating season. The substance responsible for olfactory stimulation of sexual behaviour in the camel has not been identified (Novoa, 1970).

In conclusion, our study showed that PMSG is able to induce a fertile oestrus in the camel during the last part of seasonal anoestrus, but the ensuing pregnancy is not maintained. It is possible that replacement therapy with progesterone (to supplement the inadequate functioning of the CL) shortly after mating would permit maintenance of early pregnancy.

This research was conducted partly with the support of Aleck and Rosa Sacks of Jerusalem, Israel. We thank Mrs Simy Weil for technical assistance.

\section{References}

Abdel-Raouf, M., Fateh EI-Bab, M.R. \& Owaida, M.M. (1975) Studies on reproduction in the camel (Camelus dromedarius). V. Morphology of the testis in relation to age and season. J. Reprod. Fert. 42, 109-116.

Arthur, G.H. (1975) Veterinary reproduction and obstetrics. In The Detection of Pregnancy in the Mare, 4th edn, pp. 53-60. Bailliere Tindall, London.

Bedrak, E., Chap, Z. \& Fried, K. (1979) Relationship between serum concentration of gonadotrophins and testosterone in heat-exposed ageing male rats. Exp. Gerontol. 14, 193-199.

Bedrak, E., Rosenstrauch, A., Kafka, M. \& Friedländer, M. (1983) Testicular steroidogenesis in the camel (Camelus dromedarius) during the mating and the nonmating season. Gen comp. Endocr. 52, 255-264.

Bodenheimer, F.S. (1954) Biology of Deserts. Institute of Biology, London.

Charnot, Y. (1964) Le cycle testiculaire du Dromadaire, Bull. Soc. Sci. nat. phys. Maroc 44, 37-45.

de Reviers, M.M. \& Mauleon, P. (1973) Effects of the gonadotropine hormones on the immature rat ovaries. Annls Biol. anim. Biochim. Biophys. 13, 177 193.

Dott, H.M., Hay, M.F., Cran, D.G. \& Moor, R.M. (1979) Effect of exogenous gonadotrophin (PMSG) on the antral follicle population in the sheep. $J$. Reprod. Fert. 56, 683-689.
Elias, E., Bedrak, E. \& Yagil, R. (1984a) Peripheral blood levels of progesterone in female camels during various reproductive stages. Gen. comp. Endocr. 53, 235-240.

Elias, E., Bedrak, E. \& Yagil, R. (1984b) Oestradiol concentration in the serum of the one-humped camel (Camelus dromedarius) during the various reproductive stages. Gen. comp. Endocr. 56, 258-264.

Friedländer, M., Rosenstrauch, A. \& Bedrak, E. (1984) Leydig cell differentiation during the reproductive cycle of the seasonal breeder Camelus dromedarius: An ultrastructural analysis. Gen. comp. Endocr. 55, 111.

Mehta, U.S., Prakash, A. \& Singh, M. (1962) Gestation period in camels. Indian vet. J. 39, 387.

Monniaux, D., Chupin, D. \& Saumande, J. (1983) Superovulatory responses of cattle. Theriogenology 19, 55-81

Monniaux, D., Mariana, J.C. \& Gibson, W.R. (1984) Action of PMSG on follicular populations in the heifer. J. Reprod. Fert. 70, 243-253.

Musa, B.E. \& Abusineina, M.E. (1978a) Clinical pregnancy diagnosis in the camel and a comparison with bovine pregnancy. Vet. Rec. 102, 7-10.

Musa, B.E. \& Abusineina, M.E. (1978b) The oestrous cycle of the camel (C. dromedarius). Vet. Rec. 103, 556-557. 
Nawito, M., Shalash, M.R., Hoppe, R. \& Rakha, A.M. (1967) Reproduction in female camel Bull. Nat. Res. Center, Cairo, No. 2.

Novoa, C. (1970) Review : reproduction in Camelidae. $J$. Reprod. Fert. 22, 3-20.

Shalash, M.R. (1965) Some reproductive aspects in the female camel. Wld Rev. Anim. Prod. 1, 103-108.

Shalash, M.R. (1980) Reproduction in camels. Proc. 9th Int. Congr. Anim. Reprod. \& A.I., Madrid 2, 559-564.

Sharma, S.S. (1981) Studies on sexual physiology of stud camel (Camelus dromedarius). Indian vet. J. 58, 743744.
Staigmiller, R.B. (1982) Folliculogenesis in the bovine. Theriogenology 17, 43-51.

Volcani, R. (1954) Seasonal variation in spermatogenesis of some farm animals under the climatic conditions of Israel. Refuah Vet. 11, 169-174.

Yagil, R. \& Etzion, Z. (1980) Hormonal and behavioural patterns in the male camel (Camelus dromedarius). $J$. Reprod. Fert. 58, 61-65.

Yuzlikaev, R.D. \& Akhmediev, A. (1965) Rapid reproduction in camels. Zhivotnovodstvo Mosk. 27, 61 .

Received 25 September 1984 